\title{
Indicadores Sócioeconômicos da Gestão Pública: Quão Relevantes Vocês São?
}

\author{
Clebson Santos de Brito ${ }^{1}$; Maria Rosa Rodrigues da Silva ${ }^{2}$; Nildo Ferreira Cassundé Júnior ${ }^{3}$
}

\begin{abstract}
Resumo: O estudo da eficácia das políticas públicas e os programas de desenvolvimento econômico e social das unidades da federação brasileira vem sendo feitos, de forma quantitativa, por meio dos indicadores socioeconômicos. Surge então, diante do levantamento, processamento e a gama de significados destas estatísticas, uma série de ponderações e desafios. Este estudo teve por designo analisar de forma crítica os pontos fortes e os aspectos frágeis de uma gama de indicadores. No tocante a estratégia metodológica adotada na pesquisa, este estudo qualitativo pode ser classificado de caráter eminentemente bibliográfico, exploratório e descritivo. Os resultados revelam a importância dos indicadores polarizada por forças antagônicas. Onde os indicadores, apesar de revelarem-se norteadores para a gestão pública ao captar um aspecto da realidade, devido fatores tecnicamente inviáveis de serem qualificados por meio de índices, se tornam insuficientes de representar as peculiaridades e especificidades de cada região.
\end{abstract}

Palavras-chave: Indicadores Socioeconômicos. Politicas Públicas. Gestão Pública. Qualitativo.

\section{Socioeconomic Indicators of Public Management: How Relevant You Are?}

\begin{abstract}
The study of the effectiveness of public policies and economic and social development programs of the units of the Brazilian federation has been made, quantitatively, by means of socio-economic indicators. After the aquisition of data arise the processing and the range of meanings of these statistics, a number of considerations and challenges. This study aimed the critical analysis of the strengths and the weak points of a range of indicators. Regarding the methodological strategy adopted in the survey, this qualitative study can be classified as essentially bibliographic, exploratory and descriptive. The results show the importance of indicators polarized by opposing forces. Where the indicators, although proven to be guiding for public management to capture an aspect of reality, because technically unfeasible factors to be qualified through rates, are not sufficient to represent the peculiarities and specificities of each region.
\end{abstract}

Keywords: Socioeconomic indicators. Public policy. Public administration. Qualitative.

\section{Contextualização}

A mensuração dos aspectos socioeconômicos vem adquirindo importância à medida que as informações, como o Portal da Transparência (CGU, 2016), se tornam cada vez mais acessíveis a gestores e a população em geral.

\footnotetext{
${ }^{1}$ Graduação em Administração Pública pela Universidade Federal de Alagoas, Brasil. Técnico em Informações Geográficas e Estatíst da Fundação Instituto Brasileiro de Geografia e Estatística , BrasilE-mail: clebsonsantosdebrito@gmail.com;

${ }^{2}$ Graduação em Ciências Contábeis pela Faculdade de Ciências Aplicadas e Sociais de Petrolina, Brasil. Contadora da Faculdade de Ciências Aplicadas e Sociais de Petrolina, Brasil. E-mail: rosarodrigues31@ yahoo.com.br;

${ }^{3}$ Professor Adjunto I e membro do Colegiado de Eng ${ }^{a}$ de Produção da Univasf. Doutor em Administração - PROPAD/UFPE; Mestre em Economia com ênfase em Comércio Exterior e Relações Internacionais - PIMES/UFPE ; MBA em Finanças Corporativas (MBA-DA/UFPE e Eng ${ }^{\circ}$ Civil - POLI/UPE. E-mail: nildo.cassunde@univasf.edu.br
} 
Estas informações alimentam diariamente a base de dados dos mais variados indicadores, como os indicadores socioeconômicos. E por meio destas é que os gestores públicos [devem se embasar para tomar ou] tomam suas decisões. Neste sentido, faz-se necessário mensurar, transformando os dados em indicadores, índices, capazes de serem usados como parâmetros, sinalizando nuances e múltiplos aspectos da população. O levantamento, processamento e a gama de significados desta estatística, no entanto, são abarrotados de desafios. Diante de tais desafios, está o fato dos fenômenos investigados pelas ciências sociais serem dinâmicos e complexos. E neste sentido permitir que sejam analisados e interpretados por meio de uma única perspectiva. Aos indicadores empregados para mensuração dos fenômenos sociais é dado o nome de "indicadores sociais" ou “indicadores socioeconômicos" (SOLIGO, 2012).

Entende-se por indicadores os recursos metodológicos capazes de representar ao mesmo tempo que desenha algum recorte das mazelas sociais. Jannuzzi $(2012$, p. 50) afirma que são recursos capazes de permitir a "modelização do Social". Como fotografias, os indicadores conseguem capar em frames, parte da realidade, de acordo com a perspectiva do observador. E assim, "como retratos, são estáticos, não podem sintetizar toda a multidimensionalidade da realidade social" (JANNUZZI, 2012, p. 50). Ademais, fixar-se em um ângulo e posição, pode, entre outros aspectos, revelar, segundo Bardin (2010), as limitações do observador assim como seu discurso.

Para a correta interpretação do fenômeno social é preciso que esta seja feita considerando a diversidade de aspectos na tentativa de captar o máximo de suas múltiplas dimensões analíticas. Soligo (2012), em uma lista, exemplifica que é possível captar informações das mais variadas questões sociais, como: distribuição de renda, miséria, mortalidade infantil, criminalidade, qualidade da educação. O autor (2012, p. 16-17) complementa afirmando que "os dados estatísticos passam a fazer parte do monitoramento das ações governamentais pela sociedade civil. Isso gera a necessidade da produção de informações que permitam um acompanhamento das mudanças da realidade social da população".

Neste contexto, a descentralização administrativa e tributária em favor dos municípios e a institucionalização do processo de planejamento público em âmbito local, em decorrência da constituição de 1988, têm proporcionado uma crescente demanda por informações sociais e demográficas para fins de formulação de políticas públicas municipais (JANNUZZI, 2002b; 2012). Para tanto, os inúmeros municípios, em especial os de pequeno e médio porte, a fim de subsidiar a elaboração de seus planos de ação, passaram a munir-se das estatísticas advindas dos indicadores. O resultado é que para construir planos diretores de desenvolvimento urbano e planos plurianuais de investimentos, por exemplo, segundo Jannuzzi (2012; 2002a), estas esferas públicas lançam mão das séries de indicadores sociodemográficos (como também são denominados os indicadores) das mais variadas agências estatísticas, sejam elas de consultoria privada como as ligadas ao planejamento público. 
Diante deste cenário de boas intenções com as quais são criados os indicadores, encontra-se o Brasil. Um país continental, repleto de diversidade cultural, social e econômica (IPEA, 2013). Realidade esta que permeia de complexidades os debates em torno das políticas públicas. Neste sentido, o IPEA (2015) observa que, para cumprir as mais de 15 metas assumidas na ONU até 2030, o Brasil precisará superar entraves econômicos e sociais históricos.

Em favor deste desafio estão as estatísticas sinalizando que por mais de uma década, o Brasil colecionou um crescimento favorável com percentuais considerados de significativa magnitude em diversas linhas (CRUZ et al, 2012; IPEA, 2015). O aumento da renda familiar contribuiu para a diminuição da desigualdade e o acréscimo no rendimento das famílias de baixa renda colaborou para a redução dessa disparidade social. Na educação, foi observado um crescimento na frequência escolar de todas as faixas etárias, combatendo o analfabetismo gradativamente em todas as idades (MARINHO; LINHARES; CAMPELO, 2011). No tocante a qualidade de vida (KEINERT; KARRUZ, 2002), a saúde, segundo Brasil (2013), tem-se registrado aumentos na expectativa de vida da população brasileira.

Diante deste quadro, registros revelam um nordeste, quando comparado às demais regiões, com seus índices apresentando significativas disparidades. Onde um dos requisitos tem sido o atraso com que tem se dado o modus operandi das políticas públicas (GUIMARÃES-IOSIF; ZARDO, 2015) como a qualidade da educação na escola pública (CUNHA; JESUS; GUIMARÃES-IOSIF, 2014), por exemplo. Qualidade esta que, mesmo apresentando indicativos de melhoria como a internacionalização de estudantes das escolas públicas (SCÁRDUA et al, 2012), ainda carece de muita iniciativa em parcerias para ser considerada digna, destacam BBC Brasil (2002) e Benedetti (2013). Sendo assim, a [falta de] práticas adequadas na gestão pública torna-se um fator de impacto direto nos indicadores socioeconômicos.

Neste cenário, o nordeste brasileiro, mesmo tendo passado por mudanças significativas no tocante ao circulo econômico de suas atividades (HOLANDA, 2014), segundo Oliveira, Givisiez e Sardemberg (2012) tem acompanhado a estatística nacional. Por vezes, devido ao gap de desenvolvimento existente entre o nordeste e os estados centro-sul do país, as estatísticas revelam um acelerado avanço no sentido do progresso socioeconômico. Neste sentido, quanto ao comportamento de crescimento para o mercado de trabalho (DIEESE, 2014), este tem seguido crescente na contramão do trabalho infantil, refletindo a reintegração das crianças na rede escolar (BRASIL, 2013).

Em se tratando do avanço promovido aos estados nordestinos, depois de um período de "isolamento regional e letargia" (ARAÚJO, SOUZA, LIMA, 1997, p.55), a região tem presenciado crescentes avanços em sua economia, principalmente pelo papel do estado ao desenvolver estratégias de investimento, como os complexos industriais e os centros universitários. Onde no tocante aos complexos industriais é possível listar na Bahia o Complexo Petroquímico de Camaçari (BAHIA, 2013); no Maranhão, o Projeto Siderúrgico (PESTANA, 2015); no Rio Grande do Norte, 
investimentos no Setor Petroquímico (CORTÊS, 2015); em Sergipe, com investimentos em gás natural, petróleo e sais de potássio (MDIC/SEDETEC, 2011); em Pernambuco, com o Complexo de Suape (SUAPE, 2015), entre tantos outros. E no tocante aos centros universitários é possível listar as políticas públicas de expansão dos centros universitários e a ressignificação dos antigos Centro Federal de Educação Tecnológica para Institutos de Ensino Superior (MEC, 2105).

A fim de permitir um programa de desenvolvimento econômico e social os estados da Bahia e de Pernambuco instituíram programas de desenvolvimento estaduais, a saber: dos municípios do estado da Bahia, o decreto 12.354/2010, instituiu o Programa Territórios de Identidade (BAHIA, 2010); em Pernambuco, foi subdividido em regiões de desenvolvimento (PERNAMBUCO, 2003). Esta proposta trata do regionalizar na busca de auxiliar na definição de políticas públicas a partir da perspectiva do desenvolvimento regional (BLATT; TORT, 2012).

Neste sentido, diversos trabalhos tem cercado a realidade brasileira de otimismo seja na área da saúde pública (BRASIL, 2013), com aumento da expectativa de vida (VIEGAS; CARMO; LUZ, 2015) e a redução da miséria nas estatísticas (BRASIL, 2013), seja na educação pública (CUNHA; JESUS; GUIMARÃES-IOSIF, 2014; GUIMARÃES-IOSIF; ZARDO, 2015; SCÁRDUA et al, 2012; BBC BRASIL, 2002; BENEDETTI, 2013), além de outras que sinalizam tendências (DIEESE, 2014; IPEA, 2011) dificilmente imagináveis ao analisar o Brasil de aproximadamente 20 anos atrás (OLIVEIRA; GIVISIEZ; SARDEMBERG, 2012).

No tocante ao estudo e o trato dos indicadores, um estudioso em especial se destaca neste cenário Prof. Dr. Paulo Jannuzzi e seus seguidores. Com estudos que datam desde 1993 (JANNUZZI, 1993) tem-se desenvolvido, catalogados em periódicos, livros e anais, mais de 100 obras a respeito do assunto (JANNUZZI, 1993, 1994a, 1994b, 1995, 2000; BRANDÃO, JANNUZZI, 1995; DINI et al, 1999; JANNUZZI et al, 2014) com estudos também de caráter qualitativo (JANNUZZI, BAENINGER, 1996; JANNUZZI, 2003; JANNUZZI, MARTIGNONI, SOUTO, 2012), especialmente com propostas críticas a respeito dos indicadores sociais (JANNUZZI, 2002, 2011, 2014). Apesar do mesmo ter desenvolvido em alguns momentos análises críticas no que tange a utilização dos indicadores, não existe registros de que ele e nem outro pesquisador tenha buscado compilar uma série de indicadores observando suas nuances ao mesmo tempo da ponderação de seus pontos fracos.

Frente a tantos aspectos, interessa, portanto, refletir sobre o fato de que, sem a construção de instrumentos e indicadores estatísticos que permitam avaliar as consequências e interpretar os resultados decorrentes da ação política, dificilmente será possível uma orientação consistente da tomada de decisão de política econômica (DAMÁSIO; MAH, 2011).

Sendo assim, diante da importância que tem sido depositada aos indicadores socioeconômicos, esta pesquisa tem como objetivo principal analisar de forma crítica os pontos fortes e os aspectos frágeis de uma gama de indicadores por meio da seguinte inquietação: Indicadores socioeconômicos - 
quão relevantes vocês são? Neste contexto que se inicia o ensaio com uma meditação a propósito da eventual debilidade dos indicadores socioeconômicos mais utilizados pelos gestores públicos do mainstream. E, assim sendo, para tal designo, foi feito o estudo dos Indicadores Econômicos; Indicadores de Renda; Indicadores de Desigualdade; Indicadores de Educação; Indicadores de Demografia e Saúde; Indicadores de Vulnerabilidade Social; Indicadores de Segurança Pública; Indicadores de Habitação; e Indicadores de Trabalho.

Este trabalho encontra-se estruturado da seguinte forma além desta introdução: inicialmente os aspectos metodológicos do estudo, na 'seção 2.', seguido da caracterização dos indicadores e suas conseguintes análises, na 'seção 3.', e, por fim, as considerações finais desta investigação contendo propostas para estudos futuros.

\section{Estratégia Metodológica}

A partir da problemática de pesquisa, o objetivo e o tema a ser pesquisado, efetuou-se uma investigação de natureza qualitativa, de caráter exploratório combinado com descritivo (MARCONI; LAKATOS, 2003).

Diz-se exploratório devido a necessidade de formular hipóteses operacionalizáveis (GIL, 2002) ao mesmo tempo que, após conhecer as características do fenômeno, foi possível proporcionar explicações precisas quanto ao fenômeno (RICHARDSON, 2007). No mais, tendo em vista que a pesquisa teve por finalidade desenvolver, esclarecer e ampliar o escopo das ideias, os procedimentos de amostragem e técnicas quantitativas de coleta de dados não são costumeiramente aplicados nesta pesquisa (GIL, 2002). Diz-se descritivo pois se dispõe a trabalhar características dos indicadores (VERGARA, 2003) ao mesmo tempo que se estabeleceu, quando oportuno, as relações entre estes (GIL, 2002). Em tempo, é importante salientar que as pesquisas descritivas juntamente com as exploratórias são as que habitualmente realizam os pesquisadores sociais engajados com a atuação prática.

De acordo com a triangulação dos dados, ou seja, utilização de diferentes tipos de dados (YIN, 2010), e após definir a unidade de análise, a coleta ocorreu por meio de análise documental e bibliográfico.

A estratégia metodológica constituiu em definir, preliminarmente, um quadro de conceitos referenciais dos indicadores, a partir do qual se iniciou a revisão de literatura sobre o tema ao mesmo tempo que se levantava parte dos dados que culminariam na seção de análise. Sendo assim, a pesquisa bibliográfica foi adotada como fonte para desenvolvimento das ideias centrais, apropriando-se do potencial de se desenvolver um estudo sistematizado desenvolvido com base em material publicado em periódicos, livros e bases de dados, por exemplo (VERGARA, 2003). 
Tendo em vista a existência dos mais variados indicadores (DAMÁSIO; MAH, 2011; CEPI DSS/ENSP - FIOCRUZ, 2016; IBGE, 2013; SIEDENBERG, 2003; PNUD, 2016), é importante salientar que o recorte se deu preferencialmente para o âmbito de subsídio das políticas públicas municipais. Portanto, os indicadores foram coletados, a fim de identificar características e principalmente as fragilidades dos indicadores destacando, quando possível, seus pontos negativos. Os indicadores foram selecionados por abrangerem um contexto capaz de caracterizar a rede municipal. Optou-se por tal recorte, visto que estes tratam-se da menor esfera pública onde a população tem mais possibilidade de participar ativamente das tomadas de decisões referente a todas as áreas de abrangências desde a saúde, educação, ação social, infraestrutura, entre outras.

A investigação ocorreu no primeiro semestre de 2016. O método de análise escolhido foi a análise de conteúdo, tendo como referência Bardin (2010). Já que este método possibilita a descrição do conteúdo expresso das comunicações que são empreendidas e, por vezes por meio de figuras de linguagem, são submetidas à interpretação inferencial. Para tanto, a análise, primeiro, compreendeu os dados coletados ao mesmo tempo que confirmou os pressupostos da pesquisa, e culminou ampliando o conhecimento sobre o assunto pesquisado (MINAYO, 2004). A análise de conteúdo é um instrumento de pesquisa que se constitui em um conjunto de técnicas de análises das comunicações, sejam estas escritas ou faladas. A análise do conteúdo latente ressalta a subjetividade, busca os significados encobertos e os sentidos subentendidos nas falas dos autores. Cabe observar que, na busca por uma compreensão mais aprofundada, não é possível ignorar o conteúdo latente das mensagens (TRIVIÑOS, 1987; MORAES, 1999).

Dessa forma, para atender ao objetivo da pesquisa foram realizadas as seguintes etapas: (i) Levantamento de Dados: fazer levantamento dos principais indicadores socioeconômicos com nível de desagregação municipal e pesquisar os conceitos, métodos de cálculo, todos computados por instituições com tradição e credibilidade, como IBGE, IPEA, SEI, PNUD, etc. para os municípios; (ii) Qualificação dos Indicadores municipais: fazer um tratamento dos principais indicadores socioeconômicos com nível de desagregação municipal analisando potencialidades, limitações e fragilidades dos indicadores e, assim determinando, quando possível, os aspectos negativos. Nesta etapa se optou em fazer uma análise crítica e reflexiva dos indicadores sociais e econômicos mapeados; e (iii) Sugestões para pesquisas futuras: sugerir, a partir dos aspectos dos indicadores analisados, estudos futuros. A interpretação dos dados está localizada no decurso da análise da pesquisa incluindo as inferências interpretativas durante todo o processo analítico.

Em relação à confiabilidade adotou-se um protocolo e uma base de dados desenvolvida com as categorias de análise, além dos documentos consagrados, especialmente, pelo Dr. Paulo Jannuzzi. A confiabilidade trata garantir que o pesquisador, caso siga o mesmo procedimento conforme descrito pelo inicial e conduza o mesmo estudo novamente, deverá obter os mesmos achados e conclusões. A seguir um panorama geral dos indicadores pesquisados. 
Na sequência são apresentados aspectos gerais dos índices pesquisados.

\section{Caracterização dos Indicadores}

A seguir (Quadro 1) encontram-se os principais indicadores socioeconômicos com nível de desagregação municipal e suas respectivas ponderações técnicas.

Quadro 1 - Principais indicadores socioeconômicos com nível de desagregação municipal

\begin{tabular}{|c|c|c|}
\hline $\begin{array}{c}\text { Indicador } \\
\text { Socioeconômico } \\
\end{array}$ & $\begin{array}{l}\text { Instituição } \\
\text { promotora }\end{array}$ & Características Técnicas \\
\hline $\begin{array}{c}\text { Produto Interno Bruto } \\
\text { Municipal }\end{array}$ & IBGE & $\begin{array}{l}\text { Bens e serviços produzidos no país, descontadas as } \\
\text { despesas com os insumos utilizados no processo de } \\
\text { produção durante o ano. É a medida do total do valor } \\
\text { adicionado bruto gerado por todas as atividades } \\
\text { econômicas (IBGE, 2015, p.37). } \\
\text { A metodologia de cálculo do PIB dos Municípios baseia- } \\
\text { se na distribuição pelos municípios do valor adicionado } \\
\text { das atividades econômicas das Contas Regionais do Brasil, } \\
\text { construídas pelos Órgãos Estaduais de Estatística, } \\
\text { Secretarias Estaduais de Governo e Superintendência da } \\
\text { Zona Franca de Manaus - SUFRAMA, sob a orientação da } \\
\text { Coordenação de Contas Nacionais, do IBGE (IBGE, 2004, } \\
\text { p.14). }\end{array}$ \\
\hline $\begin{array}{l}\text { Índice de Performance } \\
\text { Econômica / Índice de } \\
\text { Performance Social }\end{array}$ & SEI & $\begin{array}{l}\text { São indicadores sintéticos que mensuram "a capacidade } \\
\text { dos municípios em atender as necessidades de serviços } \\
\text { básicos da população" (SEI,2013, p.2), segundo as } \\
\text { dimensões econômica e social, respectivamente. } \\
\text { O Índice de Performance Econômica (IPE) é constituído } \\
\text { dos seguintes indicadores: Índice de Infraestrutura, Índice } \\
\text { do Produto Municipal, Índice de Corrente de Comércio } \\
\text { Exterior e Índice de Independência Fiscal. O Índice de } \\
\text { Performance Social (IPS) é composto dos seguintes } \\
\text { subíndices: Índice do Nível de Saúde, Índice do Nível de } \\
\text { Educação, Índice da Oferta de Serviços Básicos e Î́ndice } \\
\text { do Mercado de Trabalho (SEI,2013, p.4-6). Conforme o } \\
\text { método, os municípios são classificados em ordem } \\
\text { decrescente em cada índice, calculado através da média } \\
\text { geométrica dos escores padronizados de cada um deles. O } \\
\text { escore padronizado de cada indicador referente aos } \\
\text { municípios. }\end{array}$ \\
\hline $\begin{array}{c}\text { Índice de } \\
\text { Desenvolvimento } \\
\text { Humano Municipal }\end{array}$ & PNUD & $\begin{array}{l}\text { O Índice de Desenvolvimento Humano Municipal (IDHM) } \\
\text { é uma medida composta de indicadores de três dimensões } \\
\text { do desenvolvimento humano: longevidade (representada } \\
\text { pelo indicador Expectativa de Vida ao Nascer), educação } \\
\text { (composta pelos indicadores Escolaridade da População } \\
\text { Adulta, com peso 1, e Fluxo Escolar da População Jovem, } \\
\text { com peso 2), e renda (constituída pelo indicador Renda per } \\
\text { Capita) (PNUD, 2013, p.27-29). } \\
\text { De acordo com a metodologia de cálculo, inicialmente é } \\
\text { calculada a média geométrica dos componentes da } \\
\text { dimensão educação, considerando seus respectivos pesos, } \\
\text { e então se calcula a média geométrica dos valores das três } \\
\text { dimensões do desenvolvimento humano (PNUD, 2013, } \\
\text { p.29). O IDHM apresenta variação entre } 0 \text { e } 1 \text {, sendo que, } \\
\text { quanto mais próximo de 1, maior é o desenvolvimento } \\
\text { humano (PNUD, 2016). }\end{array}$ \\
\hline Índice Firjan de & FIRJAN & O Índice Firjan de Desenvolvimento Municipal (IFDM) é \\
\hline
\end{tabular}




\begin{tabular}{|c|c|c|}
\hline $\begin{array}{c}\text { Desenvolvimento } \\
\text { Municipal }\end{array}$ & & $\begin{array}{l}\text { um indicador composto que aborda, com igual ponderação, } \\
\text { três áreas do desenvolvimento humano: Emprego \& } \\
\text { Renda, educação e Saúde. O IFDM consolida em um único } \\
\text { número o nível de desenvolvimento socioeconômico local, } \\
\text { através da média simples dos resultados obtidos em cada } \\
\text { uma dessas três vertentes. O índice varia de } 0 \text { a } 1 \text {, sendo } \\
\text { que, quanto mais próximo de } 1 \text {, maior o desenvolvimento } \\
\text { da localidade. Com o objetivo de estabelecer valores de } \\
\text { referência que facilitem a análise, foram convencionados } \\
\text { quatro conceitos para o IFDM: } \\
\text { - Municípios com IFDM entre } 0,0 \text { e } 0,4>\text { baixo estágio } \\
\text { de desenvolvimento; } \\
\text { - Municípios com IFDM entre } 0,4 \text { e } 0,6 \\
\text { desenvolvimento regular; } \\
\text { - Municípios com IFDM entre } 0,6 \\
\text { - desenvolvimento moderado; } \\
\text { - Municípios com IFDM entre } 0,8 \text { e } 1,0>\text { alto estágio de } \\
\text { desenvolvimento (FIRJAN, } 2015, \text { p. } 1 \text { ). }\end{array}$ \\
\hline Índice de Gini & $\begin{array}{l}\text { PNUD } \\
\text { FJP } \\
\text { IPEA }\end{array}$ & $\begin{array}{l}\text { É um instrumento usado para medir o grau de } \\
\text { concentração de renda. Ele aponta a diferença entre os } \\
\text { rendimentos dos mais pobres e dos mais ricos. } \\
\text { Numericamente, varia de } 0 \text { a } 1 \text {, sendo que } 0 \text { representa a } \\
\text { situação de total igualdade, ou seja, todos têm a mesma } \\
\text { renda, e o valor } 1 \text { significa completa desigualdade de } \\
\text { renda, ou seja, se uma só pessoa detém toda a renda do } \\
\text { lugar (PNUD;IPEA;FJP, 2013). Conforme IPECE (2016), } \\
\text { o índice de gini é uma média. }\end{array}$ \\
\hline $\begin{array}{l}\text { Existência de Plano } \\
\text { Diretor Municipal }\end{array}$ & IBGE (Munic) & $\begin{array}{l}\text { O artigo } 182 \text { da Constituição Federal de } 1982 \text { estabelece } \\
\text { que o Plano Diretor Municipal é o instrumento básico do } \\
\text { ordenamento territorial urbano, devendo definir qual deve } \\
\text { ser o uso e as características de ocupação de cada porção } \\
\text { do território municipal, fazendo com que todos os imóveis } \\
\text { cumpram sua função social (IBGE, 2016, p.17). Os } \\
\text { principais informantes da Pesquisa de Informações Básicas } \\
\text { Municipais (Munic) são os gestores das prefeituras, que } \\
\text { são entrevistados, presencialmente, por técnicos do IBGE, } \\
\text { que se utilizam de um questionário para a coleta das } \\
\text { informações (IBGE, 2016, p.10). }\end{array}$ \\
\hline $\begin{array}{c}\text { Taxa de homicídios } \\
\text { (100.000 habitantes) }\end{array}$ & IPEA & $\begin{array}{l}\text { Divisão do grupo populacional multiplicado por } 100.000 \\
\text { pela população de referência. Os dados originais são } \\
\text { provenientes do SIM-DATASUS. Até } 1995 \text { as } \\
\text { informações são do CID9, a partir de } 1996 \text { são do CID10. } \\
\text { (IPEA, 2016). }\end{array}$ \\
\hline
\end{tabular}


Id on Line Revista Multidisciplinar e de Psicologia

Id on Line Multidisciplinary and Psychology Journal

\begin{tabular}{|c|c|c|}
\hline sanitário inadequados & & $\begin{array}{l}\text { domicílios particulares permanentes, multiplicado por } 100 . \\
\text { São considerados apenas os domicílios particulares } \\
\text { permanentes (PNUD; IPEA; FJP, 2013). }\end{array}$ \\
\hline $\begin{array}{c}\text { Taxa de Mortalidade } \\
\text { Infantil }\end{array}$ & $\begin{array}{l}\text { MINISTÉRIO DA } \\
\text { SAÚDE/DATASUS }\end{array}$ & $\begin{array}{l}\text { Número de óbitos de menores de um ano de idade, por mil } \\
\text { nascidos vivos, na população residente em determinado } \\
\text { espaço geográfico, no ano considerado (RIPSA, 2012). } \\
\text { Segue os métodos de cálculo: } \\
\text { - Direto: número de óbitos residentes com menos de um } \\
\text { ano de idade dividido pelo número de nascidos vivos de } \\
\text { mães residentes e o resultado multiplicado por } 1000 \text {. } \\
\text { - Indireto: Estimativa por técnicas demográficas especiais. } \\
\text { Os dados provenientes deste método têm sido adotados } \\
\text { para os estados que apresentam cobertura do Sinasc } \\
\text { inferior a 90\% ou que não atingem o valor de } 80 \% \text { de um } \\
\text { índice composto, especialmente criado, que combina a } \\
\text { cobertura de óbitos infantis com a regularidade do SIM } \\
\text { (RIPSA, 2012). }\end{array}$ \\
\hline $\begin{array}{l}\text { Índice de Evolução do } \\
\text { Emprego do CAGED }\end{array}$ & $\begin{array}{l}\text { MINISTÉRIO DO } \\
\text { TRABALHO E } \\
\text { EMPREGO }\end{array}$ & $\begin{array}{l}\text { Indica a evolução do emprego formal. É calculado tendo- } \\
\text { se por base o encadeamento das variações relativas } \\
\text { mensais desde Dezembro do ano imediatamente anterior } \\
\text { (MTE, 2013, p.2). }\end{array}$ \\
\hline Taxa de Analfabetismo & $\begin{array}{l}\text { MINISTÉRIO DA } \\
\text { SAÚDE/DATASUS }\end{array}$ & $\begin{array}{l}\text { Percentual de pessoas com } 15 \text { e mais anos de idade que } \\
\text { não sabem ler e escrever pelo menos um bilhete simples, } \\
\text { no idioma que conhecem, na população total residente da } \\
\text { mesma faixa etária, em determinado espaço geográfico, no } \\
\text { ano considerado (DATASUS, 2016). } \\
\text { Os dados foram processados pelo Instituto de Pesquisas } \\
\text { Econômicas e Aplicadas - IPEA, de acordo com os } \\
\text { critérios do indicador de Taxa de alfabetização - B.1, dos } \\
\text { Indicadores e Dados Básicos da Rede Interagencial de } \\
\text { Informações para a Saúde - Ripsa (DATASUS, 2016). }\end{array}$ \\
\hline
\end{tabular}

\section{Caracterização dos Indicadores}

\section{Caracterização histórica}

A origem e desenvolvimento dos indicadores sociais estão relacionados ao surgimento do Estado de Bem Estar Social e ao robustecimento das atividades de planejamento do setor público ao longo do século XX. Embora tenham ocorrido algumas contribuições importantes para definição de um marco conceitual em indicadores sociais no século passado por sociólogos, o desenvolvimento da área apenas passou a contar com arcabouço teórico científico a partir de meados da década de 1960. Nesse período foram observadas evidências de um descompasso entre crescimento econômico e melhoria das condições sociais da população em países subdesenvolvidos. Apesar de ocorrer um crescimento no produto interno bruto de alguns países, este não era acompanhado de melhoria nas condições sociais da população, que apresentava altos níveis de pobreza e desigualdade (SICSÚ; CASTELAR, 2009).

$\mathrm{O}$ indicador PIB per capita passou a não se mostrar adequado para representar o bem-estar social e o nível de desenvolvimento socioeconômico. Em razão deste cenário, empreendeu-se um 
esforço conceitual e metodológico para desenvolver instrumentos de mensuração do bem-estar social e da mudança social nas agências de estatística dos diversos países, como o IBGE, no Brasil. A publicação dos livros Social Indicators e Toward a Social Report, em meados da década de 60, representou um marco conceitual importante que inaugurou, na época, o chamado "movimento de indicadores sociais" (JANNUZZI, 2012).

Ainda segundo Jannuzzi $(2012,2014)$, a partir de então houve a mobilização dos sistemas nacionais de produção e disseminação de estatísticas públicas para incluir novas questões em suas pesquisas e produzir relatórios sociais sistematicamente. Mas o otimismo exacerbado com as potencialidades do planejamento governamental - e do uso de indicadores sociais nas políticas públicas - no curto e médio prazo levou a um descrédito deste planejamento e, consequentemente, da finalidade e utilidade dos indicadores sociais. No entanto, esse descrédito durou pouco no Brasil em razão da institucionalização de um sistema de proteção social na constituição de 1988 e do aprimoramento de experiências de formulação e implementação de políticas públicas em estados e municípios, que mostraram a pertinência instrumental dos indicadores sociais em todas as fases do ciclo de políticas públicas (JANNUZZI, 2002).

\section{Caracterização conceitual, usos, classificação e atributos}

"No campo aplicado das políticas públicas, os indicadores sociais são medidas usadas para permitir a operacionalização de um conceito abstrato ou demanda de interesse programático na área social" (JANNUZZI, 2012, p. 20). Mas, é possível identificar índices adotados equivocadamente como forma de balizar determinadas nuances se tornando não impróprios para tomadas de decisão específicas, como o caso do IDH-M que é utilizado inapropriadamente para mensurar o grau de exclusão digital (DUTT-ROSS; LOBO; FERNANDES, 2007).

Eles se prestam a subsidiar as atividades de planejamento público e a formulação de políticas sociais nas diferentes esferas de governo, possibilitam o monitoramento das condições de vida e bemestar da população por parte do poder público e sociedade civil e permitem o aprofundamento da investigação acadêmica sobre a mudança social e sobre os determinantes dos diferentes fenômenos sociais (JANNUZZI, 2012). Segundo o autor (2012), os indicadores podem ser classificados, sobretudo para análise e formulação de políticas sociais, segundo sua diferenciação quanto à natureza do ente indicado: se recurso (indicador-insumo), realidade empírica (indicador-produto) ou processo (indicador-processo). Segue respectivas definições e exemplos desta classificação.

Os indicadores-insumo (input indicators) correspondem às medidas associadas à disponibilidade de recursos humanos, financeiros ou equipamentos alocados para um processo ou programa que afeta uma das dimensões da realidade social. Exemplos: o número de leitos hospitalares 
por mil habitantes, o número de professores por quantidade de estudantes. Os indicadores-produto (outcome ou output indicators) são aqueles mais propriamente vinculados às dimensões empíricas da realidade social, referidos às variáveis resultantes de processos sociais complexos, como a esperança de vida ao nascer, proporção de crianças fora da escola ou nível de pobreza. Os indicadores-processo ou fluxo (throughput indicators) são indicadores intermediários, que traduzem em medidas quantitativas o esforço operacional de alocação de recursos humanos, físicos ou financeiros (indicadores insumo) para obtenção de melhorias efetivas de bem-estar (indicadores-produto), como número de consultas pediátricas por mês, merendas escolares distribuídas diariamente por aluno ou, ainda, homens-hora dedicados a um programa social (CARLEY, 1985).

Diante de tudo que já fora dito, há critérios para se escolher um indicador social em função de suas propriedades (JANNUZZI, 2002). Ainda segundo Jannuzzi, além da sua relevância para discussão da agenda da respectiva política, de sua validade em representar o conceito indicado e da confiabilidade dos dados usados na sua construção, o indicador deve:

- ter um grau de cobertura populacional adequado aos propósitos a que se presta;

- ser sensível a políticas públicas implementadas;

- ser específico a efeitos de programas setoriais;

- ser inteligível para os agentes e públicos-alvo das políticas;

- ser atualizável periodicamente, a custos razoáveis;

- ser amplamente desagregável em termos geográficos, sociodemográficos e socioeconômicos;

- gozar de certa historicidade para possibilitar comparações no tempo.

A partir de pesquisa exploratória foi realizado levantamento dos principais indicadores socioeconômicos em nível municipal. Segue Quadro 01 com qualificação dos indicadores, incluindo noções gerais, os pontos relevantes e os aspectos limitantes ou pontos negativos. 
Id on Line Revista Multidisciplinar e de Psicologia

Id on Line Multidisciplinary and Psychology Journal

\begin{tabular}{|c|c|c|c|}
\hline Indicadores & Rolovînin & Dontan Fonton & \\
\hline $\begin{array}{l}\text { Produto interno } \\
\text { bruto municipal }\end{array}$ & $\begin{array}{l}\text { Consiste no fato de que } \\
\text { existem padrões } \\
\text { internacionais para que } \\
0 \quad \text { mesmo seja } \\
\text { computado o que } \\
\text { permite comparações } \\
\text { entre os países. } \\
\text { (MENEGUIN, VERA, } \\
2012 \text { ) }\end{array}$ & $\begin{array}{l}\text { Parâmetro para medida da } \\
\text { atividade econômica na forma } \\
\text { de indicativo de crescimento. }\end{array}$ & 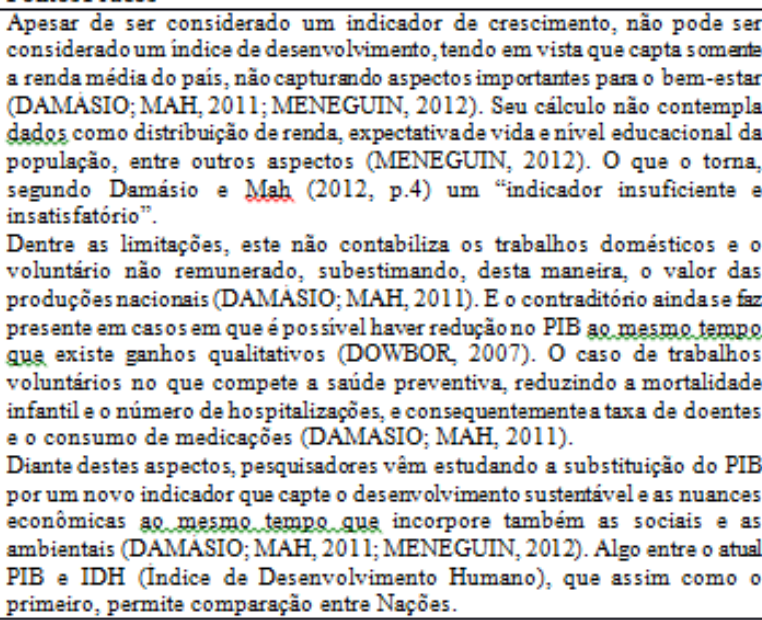 \\
\hline $\begin{array}{c}\text { Índice de } \\
\text { Performance } \\
\text { Econômica / } \\
\text { Índice de } \\
\text { Performance } \\
\text { Social }\end{array}$ & $\begin{array}{l}\text { Possuem propriedades } \\
\text { que os } r \text { tornam } \\
\text { instrumentos } \\
\text { formulação de } \\
\text { acompanhamento } \\
\text { de politicas públicas } \\
\text { (SEI, 2013, p.2). }\end{array}$ & $\begin{array}{l}\text { Permitem classificar os } \\
\text { municípios e territórios de } \\
\text { identidade, de acordo com o } \\
\text { nivel de cobertura de serviços } \\
\text { oferecidos paraa população em } \\
\text { um determinado ano de } \\
\text { referência, além de mensurar a }\end{array}$ & $\begin{array}{l}\text { Os resultados des ses indicadores não refletem integralmente a realidade } \\
\text { municipal, retratando-a apenas em parte (SEI, 2013, p.2; JANUZZI, 2012; } \\
\text { TREZNIAK, 1998, p.164). O indicador concentra-se apenas em uma análise } \\
\text { quantitativa e não capta a qualidade dos serviços ofertados, além de não haver } \\
\text { uma escala de mensuração que pos sibilite quantificar e afirmar o que é uma } \\
\text { boa performance (SEI, 2013,p.2). Como os valores obtidos dos indicadores } \\
\text { são metodologicamente padronizados em escores, tais indicadores não }\end{array}$ \\
\hline
\end{tabular}

\begin{tabular}{|c|c|c|c|}
\hline & & $\begin{array}{l}\text { capacidade dos municípios em } \\
\text { atender as necessidades de } \\
\text { serviços básicos da população, } \\
\text { bem como de nortear o bom } \\
\text { emprego dos recursos públicos } \\
\text { para mitigar eventuais } \\
\text { disparidades sociais es } \\
\text { económicas existentes (SEE, } \\
\text { 2013,p.2). }\end{array}$ & $\begin{array}{l}\text { permitem fazer análises longitudinais, permitindo apenas uma comparação } \\
\text { vertical entre os municípios (e entre estes e o estado) em certo ano e não ao } \\
\text { longo dos anos (SEI, 2013, p. 2-4). }\end{array}$ \\
\hline $\begin{array}{c}\text { Índice de } \\
\text { Desenvolvimento } \\
\text { Humano } \\
\text { Municipal }\end{array}$ & $\begin{array}{l}\text { Consiste no fato de que } \\
\text { faz um contraponto ao } \\
\text { PIB ao popularizar a } \\
\text { visão de } \\
\text { desenvolvimento } \\
\text { centrada nas pessoas e } \\
\text { não no crescimento } \\
\text { econômico, além de } \\
\text { permitir a comparação } \\
\text { entre os municipios } \\
\text { brasileiros ao longo do } \\
\text { tempo e, por } \\
\text { conseguinte, estimular } \\
\text { os formuladores e } \\
\text { implementadores de } \\
\text { politicas públicas a } \\
\text { priorizar a melhoria de } \\
\text { vida das pessoas nas } \\
\text { suas ações e tomada de } \\
\text { decisões (PNUD, } \\
\text { 2013, p.27). }\end{array}$ & $\begin{array}{l}\text { Parâmetro para identificação de } \\
\text { localidades que precisam da } \\
\text { intervenção de programas e } \\
\text { politicas específicas. } \\
\end{array}$ & 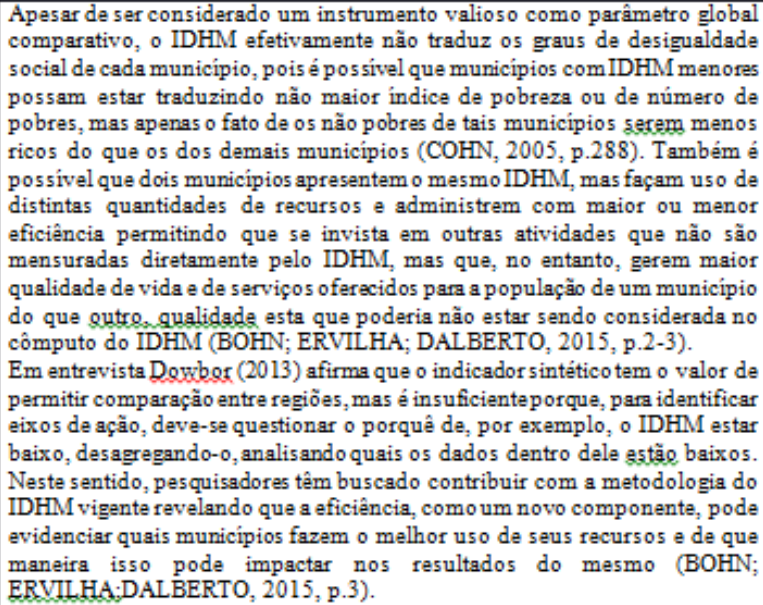 \\
\hline
\end{tabular}


Id on Line Revista Multidisciplinar e de Psicologia

Id on Line Multidisciplinary and Psychology Journal

\begin{tabular}{|c|c|c|c|}
\hline $\begin{array}{c}\text { Índice Firjan de } \\
\text { Desenvolvimento } \\
\text { Municipal }\end{array}$ & $\begin{array}{l}\text { O índice é referência } \\
\text { para o } \\
\text { acompanhamento do } \\
\text { desenvolvimento } \\
\text { socioeconômico } \\
\text { (FIRJAN, 2015, p. 11). }\end{array}$ & $\begin{array}{l}\text { Determinar com precisão se a } \\
\text { melhoria relativa ocorrida em } \\
\text { determinado município decorre } \\
\text { da adoção de politicas } \\
\text { específicas, ou se o resultado } \\
\text { obtido é apenas reflexo da } \\
\text { queda dos demais municípios } \\
\text { (FIRJAN, 2015, p.7). }\end{array}$ & $\begin{array}{l}\text { Como um indicador sintético, existem questionamentos quanto ao grau de } \\
\text { arbitrariedade com que se define os pesos através dos quais os indicadores são } \\
\text { ponderados no cômputo da medida final (JANNUZZI, 2012, p.47). } \\
\text { Em estudos semelhantes aos que vêm sendo realizados para contribuir com a } \\
\text { metodologia do IDHM, pes quisadores têm contribuido coma metodologia do } \\
\text { IFDM sugerindo a inclusão da eficiência, como um nQy cemponente, para } \\
\text { exidenciar quais municípios fazam o melhor uso de seus recurs os e de que } \\
\text { maneira is so pode impactar nos resultados do mesmo (ERVILHA; ALVES; } \\
\text { GOMES, 2013, p.108). }\end{array}$ \\
\hline $\begin{array}{c}\text { Indicador de } \\
\text { vulnerabilidade } \\
\text { social- IVS } \\
\text { (sintético) }\end{array}$ & $\begin{array}{l}\text { Destaca situações } \\
\text { indicativas de exclusão } \\
\text { e vulnerabilidade } \\
\text { social numa } \\
\text { perspectiva que vai } \\
\text { além da identificação } \\
\text { da pobreza entendida }\end{array}$ & $\begin{array}{l}\text { Pos sibilita análise comparativa } \\
\text { das conjunturas municipais e } \\
\text { sua situação nos anos } 2000 \text { e } \\
2010 \text {, contribuem para o estudo } \\
\text { das politicas públicas por } \\
\text { pesquisadores, ao identificar } \\
\text { programas e experiências bem- }\end{array}$ & $\begin{array}{l}\text { Como um indicador sintético, que agrega diversas dimens ões em seu cálculo, } \\
\text { pode apresentar fortes questionamentos quanto ao distanciamento entre o } \\
\text { conceito e a medida do indicador (JANNUZZI, 2012, p.47). } \\
\text { Tem como fontes de dados para a sua construção os censos demográficos, } \\
\text { realizados a cada } 10 \text { anos, divulgando também indicadores somente nesse } \\
\text { periodo (IPEA, 2015, p.17). Uma das qualidades desejáveis a um bom } \\
\text { indicador, para uso nas tomadas de decisão, á a disponibilidade e }\end{array}$ \\
\hline
\end{tabular}

\begin{tabular}{|c|c|c|c|}
\hline & $\begin{array}{l}\text { apenas } r \text { como } \\
\text { insuficiência de } \\
\text { recurs os monetários } \\
\text { (IPEA, 2016, p.12). }\end{array}$ & $\begin{array}{l}\text { sucedidas e replicáveis, bem } \\
\text { como mapeia desafios e } \\
\text { oportunidades locais. }\end{array}$ & $\begin{array}{l}\text { periodicidade em frequência compativel às neces sidades de sua utilização } \\
\text { (PNUD; SESI-PR, 2014, p.21). } \\
\text { A deficiência na apropriação de dados desagregados para recortes como a } \\
\text { chamada zona rural é outro fator que segue na contramão de outra qualidade } \\
\text { des ejável a um bom indicador, a desagregação, que permite foco de ação para } \\
\text { avaliar diferentes extratos sociais ou localidades (PNUD; SESI-PR, 2014, } \\
\text { p.21). }\end{array}$ \\
\hline $\begin{array}{l}\text { Existência de } \\
\text { Plano Diretor } \\
\text { Municipal }\end{array}$ & $\begin{array}{l}\text { Consiste no fato de que } \\
\text { está previsto na } \\
\text { Constituição federal } \\
\text { como instrumento } \\
\text { básico do ordenamento } \\
\text { urbano eque orienta as } \\
\text { ações dos agentes que } \\
\text { constroem eutilizam o } \\
\text { espaço urbano (IBGE, } \\
2016, \text { p.17). }\end{array}$ & $\begin{array}{l}\text { Regula o uso e a ocupação do } \\
\text { solo urbano e direciona ações } \\
\text { do poder público para } \\
\text { compatibilizar interesses } \\
\text { coletivos (IBGE, 2016, p.17- } \\
\text { 18). }\end{array}$ & $\begin{array}{l}\text { Há limitações para o uso da técnica de entrevista, utilizada para a coleta dos } \\
\text { dados do indicador, caso o pesquisador não seja uma pessoa com bastante } \\
\text { experiência ou não tiver muito bom senso: incompreensão, por parte do } \\
\text { informante, do significado das perguntas da pesquisa, que pode levar a uma } \\
\text { falsa interpretação; dificuldade de expres são e comunicação de ambas as } \\
\text { partes; ou mesmo a possibilidade de ontrevistado ser influenciado pelo } \\
\text { questionador (LAKATOS; MARCONI, 2003, p.197). }\end{array}$ \\
\hline $\begin{array}{c}\text { Taxa de } \\
\text { homicídios } \\
(100.000 \\
\text { habitantes })\end{array}$ & $\begin{array}{l}\text { As comparações sobre } \\
\text { violência envolvendo } \\
\text { paises e estados são } \\
\text { balizadas geralmente } \\
\text { por esse tipo de } \\
\text { indicador (IPEA, 2016, } \\
\text { p.10). }\end{array}$ & $\begin{array}{l}\text { Representa o indicador mais } \\
\text { tradicional para medir a } \\
\text { prevalência de homicidio nas } \\
\text { localidades (IPEA, 2016, p.10). }\end{array}$ & $\begin{array}{l}\text { O indicador é inadequado quando se objetiva avaliar a prevalência des se tipo } \\
\text { de incidente em localidades com baixo povoamento, como ocorre em quase } \\
\text { cinco mil municípios brasileiros, que possuem população inferior a } 50 \text { mil } \\
\text { habitantes (IPEA, 2016, p.10). A fim de superar este entrave, foram estimadas } \\
\text { taxas de homicidios por microrregiäo geográfica (IPEA, 2016, p.10), o que } \\
\text { permite aos gestores avaliarem a politica de segurança pública através de } \\
\text { grupo focal. }\end{array}$ \\
\hline $\begin{array}{l}\% \text { de pessoas em } \\
\text { domicilios com } \\
\text { abastecimento } \\
\text { de água e } \\
\text { esgotamento } \\
\text { sanitário. } \\
\text { inadequados }\end{array}$ & $\begin{array}{l}\text { Fundamentar planos de } \\
\text { saneamento com a } \\
\text { finalidade de eliminar } \\
\text { déficit do } \\
\text { abastecimento de água } \\
\text { e do es gotamento } \\
\text { sanitário (IBGE, 2000, } \\
\text { p. } 28 \text { ). }\end{array}$ & $\begin{array}{l}\text { Pode ser utilizado como base } \\
\text { para programas de saneamento } \\
\text { básico municipal. Permite } \\
\text { dimensionar o contingente de } \\
\text { pessoas afetadas pela situação } \\
\text { de vulnerabilidade relacionada } \\
\text { ao domicílio. }\end{array}$ & $\begin{array}{l}\text { Dados disponiveis a nivel municipal apenas nos anos em que houve censo, e o } \\
\text { indicador não capta os domicílios particulares improvisados (PNUD; IPEA; } \\
\text { FJP, 2013, p.33). Além da periodicidade de divulgação em frequência } \\
\text { decenal, não disponibiliza dados desagregados para recortes intramunicipais. } \\
\text { a despeito da neces sidade de divulgação des ses dados com frequência } \\
\text { compativel a sua utilização, bem como da necessidade de desagregação para } \\
\text { avaliação de diferentes extratos e localidades (PNUD; SESI-PR, 2014, p.21). }\end{array}$ \\
\hline
\end{tabular}




\begin{tabular}{|c|c|c|c|}
\hline $\begin{array}{c}\text { Taxa de } \\
\text { Mortalidade } \\
\text { Infantil }\end{array}$ & $\begin{array}{l}\text { Subsidia processos de } \\
\text { planejamento, gestão e } \\
\text { avaliação de politicas e } \\
\text { ações de saúde } \\
\text { voltadas para a atenção } \\
\text { pré-natal e ao parto, } \\
\text { bem como para a } \\
\text { proteção da saúde } \\
\text { infantil (RIPSA, 2012). }\end{array}$ & $\begin{array}{l}\text { Contribui na avaliação dos } \\
\text { niveis de saúde e de } \\
\text { desenvolvimento } \\
\text { socioeconômico da população, } \\
\text { prestando-se para comparaçóes } \\
\text { nacionais e internacionais } \\
\text { (RIPSA, 2012). }\end{array}$ & $\begin{array}{l}\text { Requer correção da subenumeracão de óbitos e de nascidos vivos em função } \\
\text { da persistência de sub-registro de óbitos infantis e de registros atras ados de } \\
\text { nascimento (JANNUZZI, 2012, p.39). Es sas circunstâncias impõem o uso de } \\
\text { estimativas indiretas baseadas em procedimentos demográficos específicos, } \\
\text { que podem oferecer boa aproximação da probabilidade de morte no primeiro } \\
\text { ano de vida, mas envolve, no caso das estimativas, dificuldades } \\
\text { metodológicas e imprecis ões inerentes às técnicas utilizadas, cujos } \\
\text { pres supostos podem não secumprir por mudanças da dinâmica demográfica. } \\
\text { A imprecisão é maior no caso de pequenas populações (RIPSA, 2012). A fim } \\
\text { de superar estes entraves, o indicador é apresentado apenas para municípios } \\
\text { com } 100.000 \text { habitantes (DATASUS, 2015, p.8). Outro indicador "númerode } \\
\text { óbitos infantis" é disponibilizado para os demais municípios de menor porte. }\end{array}$ \\
\hline $\begin{array}{l}\text { Índice de } \\
\text { Evolução do } \\
\text { Emprego do } \\
\text { CAGED }\end{array}$ & $\begin{array}{l}\text { Fonte para } \\
\text { acompanhamento do } \\
\text { emprego formal no } \\
\text { Brasil (MTE, 2016). }\end{array}$ & $\begin{array}{l}\text { Permite analis ar o desempenho } \\
\text { do emprego formal no aspecto } \\
\text { conjuntural em nivel de } \\
\text { desagregação municipal. }\end{array}$ & $\begin{array}{l}\text { Apesar de se constituir importante fonte para acompanhar a evolução do } \\
\text { emprego formal em nivel municipal, não dispöe de resultados para } \\
\text { municípios do estado de São Paulo com menos de } 10.000 \text { habitantes e para } \\
\text { municípios de outros estados com menos de } 30.000 \text { habitantes, conforme o } \\
\text { último censo (MTE, 2016), do ano } 2010 \text {. }\end{array}$ \\
\hline $\begin{array}{c}\text { Taxa de } \\
\text { Analfabetismo }\end{array}$ & $\begin{array}{l}\text { Dimensionar a situação } \\
\text { de desenvolvimento } \\
\text { socioeconômico de um } \\
\text { grupo social em seu } \\
\text { aspecto educacional } \\
\text { (DATASUS, 2016). }\end{array}$ & $\begin{array}{l}\text { Analisar variações geográficas } \\
\text { e temporais do analfabetismo, } \\
\text { identificando situações que } \\
\text { podem demandar necessidade } \\
\text { de avaliação mais profunda } \\
\text { (DATASUS, 2016). }\end{array}$ & $\begin{array}{l}\text { Os dados disponíveis para o indicador a nível municipal são oriundos dos } \\
\text { Censos Demográficos realizados em } 1991,2000 \text { e } 2010 \text { (DATASUS, 2016), } \\
\text { divulgados apenas em periodos decenais. } \\
\text { Uma alternativa para a escassez de dados a nível municipal em periodos } \\
\text { intercensitários, seria desagregar os dados estaduais a nívelde Regióes de } \\
\text { Desenvolvimento, como estabelecido em Pernambuco, e na Bahia, com os } \\
\text { territórios de identidade. Com a disponibilidade des ses dados, os gestores } \\
\text { locais poderão buscar soluções para as problemáticas sociais e econômicas } \\
\text { por meio de grupo focal. }\end{array}$ \\
\hline
\end{tabular}

Jannuzzi (2012) afirma que é necessário admitir os indicadores como recursos metodológicos para representação e "modelização" do Social. E como fotografias, conseguem captar estaticamente um frame da realidade, retratada de acordo com o ângulo e posição do observador. Existe toda uma realidade multidimensional em torno do desempenho econômico e social que a medida de mensuração frequentemente não consegue abranger (DAMÁSIO; MAH, 2011; JANNUZZI, 2012). E como por figura de linguagem, Jannuzzi (2012) recobra que como retratos, são estáticos, não são apropriados e nem aptos a registrar a multidimensionalidade da realidade social. O autor (2012) ainda acrescenta que para mensurar as condições de vida de uma sociedade, faz-se necessário registrar sucessivas fotografias de tal maneira que consiga compila-las em uma projeção e, ao passa-las sucessivamente, conseguir analisar sob a forma de distintos filmes, que "vão produzir imagens com melhor ou menor qualidade". O risco, acrescenta o autor (2012) é que o "foco" depende da "câmera"; e

existem câmeras ou fonte de dados mais fidedignas e existem outras câmeras ou fontes de dados que ainda não alcançaram seu nível de confiabilidade. Só usando aquela câmera, só usando aquele indicador que a gente vai conseguir perceber suas deficiências e conseguir fazer os ajustes necessários para que aquela câmera, aquela fonte de dados, produza informação de melhor qualidade ao longo do tempo.

Jannuzzi (2012), portanto, explicita de maneira metafórica como as limitações dos indicadores e o nível de confiabilidade das fontes de dados podem resultar ou não em informação de qualidade. Destaca-se a importância de se fazer um acompanhamento dos indicadores para perceber eventuais deficiências que impactem na confiabilidade e a fim de se fazer os ajustes necessários. Este ponto de vista retoma os trabalhos de Bardin (2010) e reforça a importância de se conhecer estas nuances para conseguir apropriar-se do máximo da fidelidade do cenário que o indicador se diz conseguir registrar.

Ainda a respeito é importante considerar que 
O indicador é um recurso metodológico para retratar a realidade.

O indicador é como se fosse uma fotografia, tão bom e tão ruim quanto uma fotografia.

Tão bom porque ele permite captar um aspecto da realidade e tão ruim porque ao captar um aspecto eu estou perdendo o todo.

A imagem captada por um indicador é uma redução da realidade, qualquer indicador é uma redução da realidade (JANNUZZI, 2012).

Observa-se, portanto, que os indicadores não retratam integralmente a realidade, que é muito complexa e dinâmica. Apenas apontam alguns aspectos capturados em um dado momento, quando determinada pesquisa foi a campo. Tornando-se importante, portanto, ressaltar que essa característica é comum a todos os indicadores. Segue outro autor com a mesma linha de mesmo pensamento.

Após um indicador possuir seu modus operandi padronizado, torna-se fácil mensura-lo e, portanto, cômodo fundamentar-se nele para tomar as decisões, esquecendo que não se trata da realidade no seu sentido absoluto, mas, uma expressão incompleta de uma parte dela (TRZESNIAK, 1998). Complementando, Damásio e Mah (2011) salientam a contínua necessidade da consolidação e do estímulo do aperfeiçoamento dos indicadores e medidas alternativas, de forma a diminuir as deficiências existentes nas atuais medições que servem de referência, a exemplo dos aspectos de desenvolvimento.

Ao exemplificar, Jannuzzi (2012) lança mão da análise do IDH e do EDEB e pontua:

[...] Existe uma discussão já há algum tempo no Brasil de que... eu já tinha alguma discussão sobre IDH do ponto de vista metodológico, que é o grande problema dos indicadores sintéticos. O indicador já é uma redução da realidade, não é? Uma forma muito objetivada. O indicador sintético, como o IDH, é uma composição de fotografias, esse é que é o problema. Se uma foto já reduz a realidade, imagine você tirar várias fotos e tentar encapsulá-las numa fotografia só. Ele dificulta a interpretação que a gente tem, eu sempre faço uma advocacy pelo uso de um conjunto de indicadores e não por um indicador sintético. Ainda que eu reconheça que existem indicadores sintéticos muito interessantes, o IDEB, por exemplo. É um exemplo de um bom indicador até porque ele tem só dois componentes. Porque quanto mais componentes você bota [sic] num indicador mais complicado fica de entender o que ele está medindo [...] no caso do IDH, existe uma percepção de que o IDH vem evoluindo da mesma forma no Brasil há 30 anos. No entanto, em 30 anos a gente saiu de um patamar de $13 \%$ de gasto do PIB para $20 \%$ do gasto do PIB, a gente passou de dois ou três programas universais para duzentas e tantas ações e programas governamentais na área social[...]. (JANNUZZI, 2012)

O fato é que é preferível o uso de um sistema de indicadores em detrimento do uso de indicadores sintéticos, pois, estes promovem um distanciamento do conceito que originou cada indicador componente. Não obstante, o Jannuzzi (2012) defender o IDEB, argumenta-se que o mesmo possui apenas dois componentes, que, inclusive, são da mesma dimensão (educação). Por outro lado, o IDH reúne várias dimensões (renda, educação, saúde) num só indicador, o que implica em distanciamento do conceito original e, consequentemente, da compreensão da realidade a partir dessa 
medida. Para contornar tais janelas de conflitos, onde ao tentar simplificar, o resultado tende a descaracterizar a realidade, a recomendação é assistir os indicadores de informações descritivas de cada recorte populacional e trabalhar cada política pública de modo personalizado.

\section{Considerações Finais}

$\mathrm{O}$ artigo explorou os aspectos relacionais do indicadores socioeconômicos como critério para orientação de políticas públicas. Este artigo foi motivado pela compreensão da importância dos indicadores socioeconômicos na definição das políticas públicas. A relevância do indicadores para a elaboração das estratégias e do processo decisório revela quão sério pode ser adotar determinados dados, tendo em vista que estes podem forçar um entendimento além ou aquém das necessidades da esfera pública, seja ela municipal ou estadual, por exemplo.

Constatou-se que os indicadores possuem uma abrangência por vezes incompatível com os propósitos adotados para tomadas de decisão. $\mathrm{E}$ a incapacidade do indicadores perpassam pelo fato de serem escalas resumo, de onde a partir de uma uma medida quantitativa, em seu cálculo, não tem incorporada dimensões que representem aspectos qualitativos da população. O que torna arriscado e inoportuno avaliar determinadas políticas públicas de alcance local sem antes incorporar as idiossincrasias da referida localidade.

Pautando-se nas idiossincrasias com que a população é constituída, os dados sinalizados pelos indicadores podem, a primeira vista, ser convenientemente fáceis de serem levantados, tabulados e processados, mas, não gerar um impacto ideal dos planos diretores nas políticas públicas. Em período de crises econômicas, este estudo faz um alerta para que os indicadores sejam ajustados a fim de possuir uma "lente" mais apropriada, com metadados mais adequados, tendo em vista que nem tudo que está posto é precisa ser seguido às "segas" ou no "tato".

Certo de que a informação de um dado se tornou peça importante para calibrar o grau de importância de determinada política pública, em especial em tempos de crise, onde em período de recursos ainda mais escassos se faz necessário determinar critérios de escolha para se priorizar um projeto em detrimento de outro, é primordial uma medida capaz de envolver aspectos qualitativos em seus parâmetros de prioridade.

A partir do princípio de que a meta é construir uma sociedade cada vez mais equânime, tornase necessário preparar os indicadores para que operem a partir das idiossincrasias dos múltiplos territórios do Brasil; e para tal, se faz necessário a construção indicadores que primem por dados cujos atributos avaliem as características não tão apenas a quantidade. Assim, associando aspectos qualitativos aos quantitativos se espera que seja possível desenvolver políticas públicas mais inclusivas e eficazes. 
Id on Line Revista Multidisciplinar e de Psicologia

Id on Line Multidisciplinary and Psychology Journal

Observa-se a partir dos achados que os indicadores não retratam integralmente a realidade.

Pois, proveniente da complexidade dos cenários e da dinâmica com que se movem as economias, além do próprio fato do indicador ter sido construído com falhas conceituais, tudo isso leva a distorção da realidade, distorcendo as políticas públicas, e consequentemente levando ao fracasso ou fiasco das intervenções públicas.

Os indicadores, quando muito, sinalizam alguns aspectos capturados em um dado momento, quando determinada pesquisa foi a campo, e isso é uma característica inerente a todos os indicadores, o que nem por esse motivo torna-o útil.

Como sugestão para pesquisas futuras, sugere-se que fazer um estudo qualitativo de investigação em um território de identidade ou região de desenvolvimento dos inúmeros programas de desenvolvimento setorial do Brasil, a exemplo dos existentes no estado baiano e pernambucano, respectivamente, com vista a promover o desenvolvimento econômico e social dos Municípios nele contido.

\section{Referências}

ARAÚJO, Tarcísio Patrício de; SOUZA, Ademir do Vale; LIMA, Roberta Alves. Nordeste: Economia e Mercado de Trabalho. Disponível em:<http://www.scielo.br/pdf/ea/v11n29/v11n29a04.pdf>. Acesso em: 10 abr. 2016.

BAHIA - GOVERNADOR DO ESTADO DA BAHIA. Decreto 12354/10 | Decreto $\mathbf{n}^{\mathbf{1}} \mathbf{1 2 . 3 5 4}$ de 25 de agosto de 2010. 2010.

BAHIA - Governo do Estado da Bahia. Plano Diretor - Polo Industrial de Camaçari. 2013.

BARDIN, L. Análise de conteúdo. 3. ed. Lisboa: Edições 70, 2010.

BBC Brasil. Como é possível melhorar a educação no Brasil? 21 de agosto, 2002. Disponível em: http://www.bbc.com/portuguese/forum/020819_educacaoforum.shtml . Acessado em: 13.abril.2016

BENEDETTI, Kátia Simone. A dignidade ultrajada: ser professor do ensino público nos dias atuais. 1. ed. Rio de Janeiro: Barra Livros, 2013. v. 200. 178p .

BLATT, N.; TORT, Juan. Territórios de Identidade no Estado da Bahia: Uma Análise da Regionalização Implantada pela Estrutura Governamental Para Definição de Políticas Públicas, A Partir da Perspectiva do Desenvolvimento Regional.. In: I SETED SEMINÁRIO INTERNACIONAL, ESTADO, TERRITÓRIO E DESENVOLVIMENTO, 2012, SALVADOR. COMUNICAÇÃO ORAL, 2012.

BOHN, L.; ERVILHA, G. T.; DALBERTO, C. R. IDHM e Eficiência: O Desenvolvimento Municipal Sob um Novo Prisma. ANPEC SUL 2015. Disponível em: <http://www.ppge.ufrgs.br/anpecsul2015/artigo/idhm_e_eficiencia.pdf〉. Acesso em: 21 abr. 2016. 
BRANDÃO, S. M. ; JANNUZZI, Paulo de Martino . Distribuição de renda e pobreza. São Paulo em Perspectiva (Impresso), São Paulo, v. 9, n.3, p. 101-108, 1995.

BRASIL. IBGE. Contas Nacionais 2015. Disponível em: $<\mathrm{ftp}$ //fttp.ibge.gov.br/Contas_Nacionais/Contas_Nacionais_Trimestrais/Fasciculo_Indicadores_IBGE/ pib-vol-val_201504caderno.pdf>. Acesso em: 02 abr. 2016.

BRASIL. IBGE. Produto Interno Bruto dos Municípios - Série Relatórios Metodológicos. Vol. 29, Rio de Janeiro, 2004. Disponível em : 〈http://biblioteca.ibge.gov.br/visualizacao/livros/liv4547.pdf>. Acesso em: 08 abr. 2016.

BRASIL. $\quad$ IBGE. SIDRA. Disponível em: http://www.sidra.ibge.gov.br/bda/tabela/protabl.asp?c=2906\&z=cd\&o=31\&i=P>. Acesso em: 03 abril 2016.

BRASIL. IBGE. SIDRA. Disponível em: <http://www.sidra.ibge.gov.br/bda/tabela/listabl.asp?c=3563\&z=cd\&o=17>. Acesso em: 03 abril 2016.

BRASIL. IPEA. O Índice de Desenvolvimento Humano Municipal Brasileiro. Brasília: PNUD, IPEA, $\quad$ FJP, 2013. Disponível em: http://www.ipea.gov.br/agencia/images/stories/PDFs/130729_AtlasPNUD_2013.pdf>. Acesso em: 08 abr. 2016.

CARLEY, M. Indicadores sociais: teoria e prática. Rio de Janeiro: Zahar, 1985.

CEPI DSS/ENSP - FIOCRUZ - Centro de Estudos, Políticas e Informação sobre Determinantes Sociais da Saúde, CEPI DSS/ ENSP - FIOCRUZ.

CGU - Controladoria Geral da União. Portal da Transparência. Disponível em: http://transparencia.gov.br/ . Acessado em: 10/mai/2016.

COHN, Amélia. Equiidade, saúde e critérios para alocação de recursos. Ciênc. saúde coletiva, Rio de Janeiro, v. 10, n. 2, p. 287-288, Abr. 2005. Disponível em: $<$ http://www.scielo.br/scielo.php?script=sci_arttext\&pid=S1413-

81232005000200003\&lng=en\&nrm=iso>. Acesso em: 21 Abr. 2016.

CORTÊS, Ieris Ramalho. Desenvolvimento industrial da Barrilha no Rio Grande do Norte. Baraúna. São Paulo. 2015.

CRUZ, Adriana Inhudes G.; Ambrozio, A. M. H.; PUGA, F. P.; SOUSA, F. L.; NASCIMENTO, M. M. A Economia Brasileira: conquistas dos últimos dez anos e perspectivas para o futuro. BNDES, out. 2012.

CUNHA, Célio da; JESUS, Wellington Ferreira de; GUIMARÃES-IOSIF, Ranilce. (Org.). A educação em novas arenas: políticas, pesquisas e perspectivas. 1ed.Brasília: Liber Livro, 2014, v. 1

DAMÁSIO, Bruno; Mah, Luís. Das Limitações do PIB enquanto indicador às necessidades de medição dos níveis de Desenvolvimento. Documentos de Trabalho do Centro de Estudos sobre África e do Desenvolvimento Instituto Superior de Economia e Gestão da Universidade Técnica de Lisboa - CEsA. Lisboa, n. 89. 2011 
DIEESE- Departamento Intersindical de Estatística e Estudos Socioeconômicos. O Mercado de Trabalho Formal Brasileiro: Resultados da RAIS 2013. Nota Técnica. N. 140, set-14, 2014.

DINI, N. P. ; JANNUZZI, Paulo de Martino ; FERREIRA, Maria Paula ; ARIZONO, Neuci . Renda familiar e mercado de trabalho: um balanço da década.. São Paulo em Perspectiva (Impresso), São Paulo, v. 13, n.4, p. 153-166, 1999.

DOWBOR, Ladislau. Democracia econômica: um passeio pelas teorias. Fortaleza: Banco Nordeste do Brasil, 2007.

DUTT-ROSS, S.; LOBO, L.; FERNANDES, J. M. A Utilização do IDH para Políticas Públicas de Inclusão Digital nos Municípios Brasileiros: Conceitos Metodológicos e Legitimidade desse Critério. In: Xavier, R. S.; Pimenta, M. H. C.; da Silva, L. H. R. (Org.). A Trajetória das Políticas Públicas no Brasil: Uma Reflexão Multisetorial. Porto Alegre: Sagra Luzzato, 2007, v. 1, p. 179-190.

FEDERAÇÃO DAS INDÚSTRIAS DO RIO DE JANEIRO. Índice Firjan de Desenvolvimento Municipal - Nota $\quad$ Metodológica. 2015. Disponível em: <http://www.firjan.com.br/lumis/portal/file/fileDownload.jsp?fileId=2C908A8F51466FB1015162EC2 7A4347A>. Acesso em: 21 abr. 2016.

Publicação IFDM 2015. 2015. Disponível em: < http://www.firjan.com.br/lumis/portal/file/fileDownload.jsp?fileId=2C908A8F51466FB1015164368C FF2233>. Acesso em: 21 abr. 2016.

GIL, Antonio Carlos. Como Elaborar Projetos de Pesquisa. 4. ed. São Paulo: Atlas, 2002.

Métodos e técnicas de pesquisa social. 6. ed. São Paulo: Atlas, 2008.

GUIMARAES-IOSIF, Ranilce; ZARDO, S. P. . A internacionalização da educação superior no Brasil: expansão, produção do conhecimento e desafios emancipatórios. Revista del Núcleo de Estudios e Investigaciones en Educación Superior del MERCOSUR, v. 3, p. 35-49, 2015.

HOLANDA, V. C. C.. MODERNIZAÇÕES E ESPAÇOS SELETIVOS NO NORDESTE BRASILEIRO. Revista de Geografia (Recife), v. 31, p. 1-20, 2014.

INSTITUTO BRASILEIRO DE GEOGRAFIA E ESTATÍSTICA. Uma análise das condições de vida da população brasileira 2013. 2016. Disponível em: http://www.ibge.gov.br/home/estatistica/populacao/condicaodevida/indicadoresminimos/sinteseindics ociais2013/. Acessado em 15.abril.2016

Perfil dos municípios brasileiros : 2015 / IBGE, Coordenação de População e Indicadores Sociais. - Rio de Janeiro : IBGE, 2016. 61 p. Disponível em: <http://biblioteca.ibge.gov.br/visualizacao/livros/liv95942.pdf >. Acessado em: 22 abr. 2016.

INSTITUTO DE PESQUISA E ESTRATÉGIA ECONÔMICA DO CEARÁ. Entendendo o Índice de Gini. Disponível em: < http://www.ipece.ce.gov.br/publicacoes/Entendendo_Indice_GINI.pdf>. Acesso em: 09 abr. 2016.

INSTITUTO DE PESQUISA ECONÔMICA APLICADA. Atlas da Violência 2016. Nota Técnica n.17, Diest, mar. 2016. Disponível em: <http://www.ipea.gov.br/portal/images/stories/PDFs/nota_tecnica/160405_nt_17_atlas_da_violencia_ 2016_finalizado.pdf>. Acesso em: 22 abr. 2016. 
Id on Line Revista Multidisciplinar e de Psicologia

Id on Line Multidisciplinary and Psychology Journal

Atlas da Vulnerabilidade Social nos Municípios Brasileiros. Brasília, IPEA 2015.

77p. Disponível em: <http://ivs.ipea.gov.br/ivs/data/rawData/publicacao_atlas_ivs.pdf>. Acesso em: 23 abr. 2016.

Índice de Vulnerabilidade Social. Disponível em:< http://ivs.ipea.gov.br/ivs/pt/o_atlas/ivs/>. Acesso em: 21 abr. 2016.

Ipeadata. 2016. Disponível em:<http://www.ipeadata.gov.br/>. Acesso em: 22 abr.

2016.

12, n. 86,2015

Desenvolvimento sustentável: chegaremos lá? Desafios de desenvolvimento. Ano

Um novo olhar sobre a diversidade territorial. Ano 10, ed. 77, 2013.

JANNUZZI , 2002a - JANNUZZI, Paulo de Martino. Repensando a prática de uso de indicadores sociais na formulação e avaliação de políticas públicas municipais. In: Tania Margarete Mezzomo Keinert; Ana Paula Karruz. (Org.). Qualidade de vida: observatórios, experiências e metodologias. 1ed.São Paulo: AnnaBlume, 2002, v. , p. 53-72

JANNUZZI, Paulo de Martino; BAENINGER, R. . Qualificação socioeconômica e demográfica das classes da escala ABIPEME. Revista de Administração (FEA-USP), São Paulo, v. 31, n.3, p. 82-90, 1996.

JANNUZZI, Paulo de Martino; MARTIGNONI, Enrico Moreira ; SOUTO, B. F. . O Programa Bolsa Família e sua contribuição para redução da pobreza no Brasil. Revista Brasileira de Monitoramento e Avaliação, v. 4, p. 40-61, 2012.

JANNUZZI, Paulo de Martino; NAKASHIMA, C. ; BRASILEIRO, C.E. ; SANTANA, C.H.A. . Construindo Mapas de Pobreza, Serviços Públicos e de Oportunidades para o Plano Brasil Sem Miséria. Cadernos de Estudos - Secretaria de Avaliação e Gestão da Informação, v. 19, p. 78-87, 2014.

JANNUZZI, Paulo de Martino. Avaliação de Programas Sociais no Brasil: Repensando Práticas e Metodologias das Pesquisas Avaliativas. Planejamento e Politicas Publicas, v. 36, p. 251-275, 2011.

JANNUZZI, Paulo de Martino. Avaliação de Programas Sociais: conceitos e referenciais de quem a realiza. Estudos em Avaliação Educacional (Impresso), v. 25, p. 22-42, 2014.

JANNUZZI, Paulo de Martino. Considerações sobre o uso, mau uso e abuso dos indicadores sociais na formulação e avaliação de políticas públicas municipais.. Revista de Administração Pública (Impresso), Rio de Janeiro, v. 36, n.1, p. 51-72, 2002a.

JANNUZZI, Paulo de Martino. Entrevista Assistida. Instituto Fonte e Itaú social. Publicado 24 jul. 2012. Disponível em: <https://www.youtube.com/watch?v=zRGIL1FA_MY\&feature=youtu.be>. Acesso em: 09 abr. 2016.

JANNUZZI, Paulo de Martino. Entrevista Assistida. Instituto Fonte e Itaú social. Publicado 28 abr. 2014. Disponível em:<https://www.youtube.com/watch?v=vqbknHMZL-E\&feature=youtu.be $>$. Acesso em: 09 abr. 2016.

JANNUZZI, Paulo de Martino. Estratificação sócio-ocupacional para estudos de mercado e pesquisa social no Brasil. São Paulo em Perspectiva (Impresso), São Paulo, v. 17, n.3-4, p. 247-254, 2003. 
JANNUZZI, Paulo de Martino. Fontes de indicadores sociais para Marketing.. Cadernos da FCECA (PUCCAMP), Campinas, v. 2, n.1, p. 5-12, 1993.

JANNUZZI, Paulo de Martino. Fontes de informação sócio-demográfica para planejamento no setor público. Revista de Administração Pública (Impresso), Rio de Janeiro, v. 29, n.3, p. 197-210, 1995.

JANNUZZI, Paulo de Martino. Indicadores socioeconômicos na gestão pública. Florianópolis: Departamento de Ciências da Administração/UFSC, 2012. p.01-110.

JANNUZZI, Paulo de Martino. Mudanças demográficas na última década: o que dizem os primeiros resultados do Censo 91. Cadernos da FCECA (PUCCAMP), Campinas, v. 3, n.1, p. 40-54, 1994b.

JANNUZZI, Paulo de Martino. Renda e distribuição de renda no interior paulista em 1980. Cadernos da FCECA (PUCCAMP), Campinas, v. 3, n.2, p. 59-78, 1994a.

JANNUZZI, Paulo de Martino. Repensando a prática de uso de indicadores sociais na formulação e avaliação de políticas públicas municipais. In: Tania Margarete Mezzomo Keinert; Ana Paula Karruz. (Org.). Qualidade de vida: observatórios, experiências e metodologias. 1ed.São Paulo: AnnaBlume, 2002b, v. , p. 53-72.

JANNUZZI, Paulo de Martino. Status socioeconômico das ocupações brasileiras: índices aproximativos para 1980, 1991 e anos de 1990.. Revista Brasileira de Estatística, Rio de Janeiro, v. 61, n.216, p. 47-74, 2000.

JANNUZZI. Paulo de M. Considerações sobre o uso, mau uso e abuso dos indicadores sociais na formulação e avaliação de políticas públicas municipais. Revista de Administração Pública. Rio de Janeiro. jan./fev $2002 . \quad$ Disponível em: <http://bibliotecadigital.fgv.br/ojs/index.php/rap/article/view/6427/5011>. Acesso em: 10 abr. 2016. Keinert, Tania Margarete Mezzomo; Karruz, Ana Paula (Org.). Qualidade de vida: observatórios, experiências e metodologias. 1ed.São Paulo: AnnaBlume, 2002

LADISLAU Dowbor. Entrevista Assistida. Desenvolvimento Humano em debate. Realização de PNUD. 2013. (13 min.), son., color. Série Desenvolvimento Humano em debate. Disponível em: <https://www.youtube.com/watch?v=Yf-PodBng_c >. Acesso em: 21 abr. 2016.

MARCONI, M.A.; LAKATOS, E. M. Fundamentos de metodologia científica. 5. edição. São Paulo. 2003.

MARINHO, E. L. L. ; LINHARES, F. C. ; CAMPELO, G. L. . Os Programas de Transferência de Renda do Governo Afetam a Pobreza no Brasil?. Revista Brasileira de Economia (Impresso), v. 65, p. 267-288, 2011.

MEC - Ministério da Educação. Reestruturação e Expansão das Universidades Federais. 2015.

MENEGUIN, F. B.; VERA, F. S. . Indicador de Desenvolvimento Sustentável. In: Núcleo de Estudos e Pesquisas do Senado. (Org.). Temas e Agendas para o Desenvolvimento Sustentável. Subsecretaria de Edições Técnicas do Senado. Brasília: 2012, v. 1, p. 85-88.

MINISTÉRIO DA SAÚDE. DATASUS. Informações de Saúde. Nota Técnica Indicadores Municipais, $2015 . \quad$ Disponível em:< http://tabnet.datasus.gov.br/cgi/pacto/2015/Nota_Tecnica_Indicadores_Municipais.pdf $>$. Acesso em: 23 abr. 2016. 
MINISTÉRIO DA SAÚDE. DATASUS. Informações de Saúde. Livro Indicadores e Dados Básicos - IDB. 2ed. cap.B. Disponível em:< http://tabnet.datasus.gov.br/tabdata/livroidb/2ed/CapituloB.pdf > Acesso em: 23 abr. 2016.

. Informações de Saúde. Taxa de Analfabetismo. Notas Técnicas. Disponível em:< http://tabnet.datasus.gov.br/cgi/ibge/censo/Taxa_Analfabetismo.pdf>. Acesso em: 23 abr. 2016.

MINISTÉRIO DO TRABALHO E EMPREGO. Conceituação do CAGED. 2013.Disponível em: $<$ http://acesso.mte.gov.br/lumis/portal/file/fileDownload.jsp?fileId=8A7C812D3DCADFC3013E0E2 C3AA77D4A>. Acesso em: 23 abr. 2016.

Evolução de Emprego do CAGED. 2013.Disponível em: <http://bi.mte.gov.br/eec/pages/consultas/evolucaoEmprego/consultaEvolucaoEmprego.xhtml\#relatori oSetor>. Acesso em: 23 abr. 2016.

NERI, M. Índice de Theil. Disponível em: <http://www.cps.fgv.br/cps/pesquisas/Politicas_sociais_alunos/2010/BES_raiz_aanew/pdf/sbst/BES_ Theil_Teoria.pdf>. Acesso em: 09 abr. 2016.

OLIVEIRA, Elzira Lucia de; GIVISIEZ, G. H. N. ; SARDEMBERG, K. . Trabalho Formal e Informal: um balanço das últimas duas décadas no Brasil. In: IV Congresso Português de Demografia, 2012, Évora. Livro de Resumos. Évora: Associação Portuguesa de Demografia, 2012. v. 1. p. 44-49.

PEREIRA, M. G. D. ; LIMA, R. A. ; BASTOS, C. R. P. . Experiências de migração: construções identitárias e ressignificação de. In: Liliana Cabral Bastos; William Soares dos Santos. (Org.). A entrevista na pesquisa qualitativa. Perspectivas em análise da narrativa e da interação. 1ed.Rio de Janeiro: Quartet, 2013, v. , p. 7-203.

PERNAMBUCO - GOVERNADOR DO ESTADO DE PERNAMBUCO. LEI No 12.427, DE 25 DE SETEMBRO DE 2003. Regiões de Desenvolvimento. 2003.

PESTANA, Thiago V.. Os impactos socioambientais na comunidade Pequiá de Baixo em Açailândia/MA decorrentes da atividade siderúrgica. In: II Semana de Iniciação Científica da Unidade de Ensino Superior do Sul do Maranhão, 2015, Imperatriz. II Semana de Iniciação Científica da Unidade de Ensino Superior do Sul do Maranhão, 2015.

PNUD; IPEA; FJP. Atlas do Desenvolvimento Humano no Brasil. 2013. Glossário. Brasília: PNUD Brasil, 2014. Disponível em: <http://www.atlasbrasil.org.br/2013/o_atlas/glossario/pt/>. Acesso em: 21 abr. 2016.

O Índice de Desenvolvimento Humano Municipal Brasileiro. Brasília: PNUD, Ipea, $\quad$ FJP, 2013.296 .900 Disponível <http://www.atlasbrasil.org.br/2013/data/rawData/publicacao_atlas_municipal.pdf >. Acesso em: 22 abr. 2016.

PNUD.

Atlas

Municípios.

Disponível

em: <http://www.pnud.org.br/IDH/Default.aspx?indiceAccordion=1\&li=li_AtlasMunicipios>. Acesso em: 03 abr. 2016.

O que é o IDHM. Disponível em: <http://www.pnud.org.br/idh/IDHM.aspx?indiceAccordion=0\&li=li_IDHM\#>. Acesso em: 20 abr. 2016. 
PNUD/FJP/IPEA.

$\mathbf{O}$

IDHM.

2016.

Disponível

em:

http://www.atlasbrasil.org.br/2013/pt/o_atlas/metodologia/idhm_renda/ Acessado em: 14.abril.2016

PROGRAMA DAS NAÇÕES UNIDAS PARA O DESENVOLVIMENTO - PNUD. SERVIÇO SOCIAL DA INDÚSTRIA DO PARANÁ - SESI-PR. Interpretação e Análise de Indicadores. Brasília: $\quad$ SESI-PR/PNUD, $2014 . \quad$ 88p. $\quad$ Disponível $\quad$ em: <http://www.pnud.org.br/Public/img/odm/pdf/AF_manual-PNUD_M1_indicadores.pdf $>$. Acesso em: 23 abr. 2016.

RICHARDSON, R. J. Pesquisa social: métodos e técnicas. 3. ed. ver e ampliada. São Paulo: Atlas, 2007.

RIPSA. Fichas de Qualificação de Indicadores. Disponível em:<http://fichas.ripsa.org.br/2012/>. Acesso em: 09 abr. 2016.

SCÁRDUA, M. ; GUIMARAES-IOSIF, R.; DASSOLER, O. B.; PALAZZO, J. (Org.s) . Coletânea de artigos do seminário internacional em política e governança educacional para a cidadania, diversidade, direitos humanos e meio ambiente. 1. ed. Brasília: Editora Universa, 2012. v. 1. 404p .

SICSÚ, Armando; CASTELAR, Armando (orgs.). Sociedade e Economia: Estratégias de Desenvolvimento. IPEA. Brasília, 2009.

SIEDENBERG, D. R.. Indicadores de desenvolvimento sócio-econômico: uma síntese. Desenvolvimento em Questão, Ijuí - RS, v. 1, n.-, p. 45-72, 2003.

SOLIGO, Valdecir. Indicadores: Conceito e Complexidade do Mensurar em Estudos e Fenômenos Sociais. Estudos Avaliativos em Educação. São Paulo, vol.23 n.52 p.12-25 mai/ago 2012. Disponível em:< http://www.fcc.org.br/pesquisa/publicacoes/eae/arquivos/1724/1724.pdf >. Acesso em: 10 abr. 2016.

SUPERINTENDÊNCIA DE ESTUDOS ECONÔMICOS E SOCIAIS DA BAHIA. Desenvolvimento Municipal e Eficiência dos Gastos Públicos na Bahia: Uma Análise do IFDM a partir da Metodologia DEA. IX Encontro de Economia Baiana, set. 2013. Disponível em: <http://www.eeb.sei.ba.gov.br/pdf/2013/eb/desenvolvimento_municipal.pdf $>$. Acesso em: 21 abr. 2016.

Índices de Performance Econômica e Social da Bahia. Publicações SEI. v.1 maio 2013. Disponível em:〈http://www.sei.ba.gov.br/images/indicadores_especiais/pdf/ipe_ips/analise_dos_resultados.pdf $>$. Acesso em: 20 abr. 2016.

TRZESNIAK, Piotr. Indicadores Quantitativos: Reflexões que antecedem seu estabelecimento. Brasília, v. 27, n. 2, p. 159-164, maio/ago. 1998. Disponível em:< http://www.scielo.br/pdf/ci/v27n2/2729808.pdf>. Acesso em: 10 abr. 2016.

VIEGAS, ANNA PAULA BISE ; CARMO, ROSE FERRAZ; LUZ, Zélia Maria Profeta da . Fatores que influenciam o acesso aos serviços de saúde na visão de profissionais e usuários de uma unidade básica de referência. Saúde e Sociedade (USP. Impresso), v. 24, p. 100-112, 2015.

YIN, Robert K. Estudo de caso: planejamento e métodos. 2. ed. Porto Alegre: Bookman, 2001.

ZANELLA, Liane Carly Hermes. Metodologia de estudo e de pesquisa em administração. 2. ed. reimp. - Florianópolis : Departamento de Ciências da Administração / UFSC, 2012. pág. 1-160. 
Id on Line Revista Multidisciplinar e de Psicologia

Id on Line Multidisciplinary and Psychology Journal

\section{Como citar este artigo (Formato ABNT):}

BRITO, C.S.; SILVA, M.R.R.; CASSUNDÉ JÚNIOR, N.F. Indicadores socioeconômicos na Gestão Pública: Quão Relevantes vocês São?A investigação participativa como processo de melhoria da Práxis docente. Id on Line Revista de Psicologia, Julho de 2016, vol.,10 n.30, Supl 1. p. 144-167. ISSN 1981-1179.

Recebido: 25/05/2016

Aceito: 03/06/2016 